\title{
The Relationship Between Computer Ownership and Student Achievement
}

\author{
Yuan $\mathrm{Xu}^{1,1 \mathrm{st}}$, Enyu Lin ${ }^{2,1 \mathrm{st}}$, Xihan Zhu ${ }^{3,1 \text { st }}$ \\ ${ }^{1}$ Yuan Xu: College of Letters and Science, University of California Santa Barbara, Santa Barbara, CA93106, \\ America, yuanxu@ucsb.edu \\ ${ }^{2}$ Enyu Lin: Senior in Dunn School; Fuzhou, Fujian 350001, China, 1456153430@qq.com \\ ${ }^{3}$ Xihan Zhu: Wuhan Britain-China School, Wuhan , Hubei, China 430022, xihan.zhu.0108@outlook.com
}

\begin{abstract}
Based on the research that has already been done by the Prospera program, we developed 4 statistic models to investigate the relationship between math, or Spanish, and other variables provided in a child's life. In the first model, we used regression model to see the children's 9th grade math score alone with other variables. Same with second model but with Spanish score instead of math score. And in the third and fourth model, we take out the family income variable to see its impact on children's academic score. Then we will conclude the effects of different variables based on our results from different models.
\end{abstract}

Keywords: Prospera, Mexico, Cash transfer program, regression models, math score, Spanish scores, Family incomes, variables

\section{INTRODUCTION}

As the advancement of technology, computer ownership of students has increased during several decades. Thus, it is appealing to explore the relationship between computer ownership and student achievement. In this research paper, we aim to do some analysis on this topic based on the Prospera program.

\section{LITERATURE REVIEW}

We first examine the Prospera program in Chiapas, Mexico. Using a program called conditional cash transfer(CCT) and examining its impacts on education and so on. [1] The research used ethnographic research, which include "direct observation, diary studies, video recordings, photography and artefact analysis" to provide a full picture of the subject's a day in life(Damian, the aim of ethnographic research). This will make sure that the researchers are in control or observing, all the variations in subjects' lives and based on the variation, analyze the results of the study. The study conducted a survey to 14 high school students in 2006 and a convenience sample survey of 78 high school students, who all received Prospera stipends. However, the drawbacks of the study is that the various perspectives that it provides could possibly create gaps between observations and interview results. The most significant part of this essay is that we can have a basic understanding of the program of Prospera in a limited amount of time. It's obvious that Prospera includes multiple aspects of a student's life to see the impact of the funds on a student's life, so it's important to start our own research on the impact of computers and the internet on students' academic performance with a general idea of the program. [2]

Another article that we examined in order to support our own research is Do Conditional Cash Transfers Improve Economic Outcomes in the Next Generation? Evidence from Mexico. The article analyzed the longterm impacts of Progresa on the educational, labor market, household, and demographic outcomes of its earliest beneficiaries. The data included in the research is a $10 \%$ sample of households from the Mexican Population Census of 2010. The research strategy of this study is based on spatiotemporal variation in program rollout at the municipal level and cohort variation in the age at which children received the program. [3]

The results reached by the researcher is that the offer of the program before transition from primary to secondary education has positive effects on the years of education for both men and women, and the large improvement of education will also improve the outcomes in the labor market since educated young adults 
will enter the workforce, especially for the improvement of female workforce. In addition, household housing quality and durable goods ownership for both sexes improved according to the research

The benefit that Progresa can bring is intergenerational, and the long-term effects on the next generation's completed education, work, earnings, and household economic status are significant.

The last article that we examined is How Computers are Related to Students' Performance. This article analyzed how learning outcomes are related to economies' investments in school ICT resources, and how the students' performance is associated with the use of ICT in school.

The author also draws diagrams to show the correlation between the two variables.

Then, the article evaluates the influence of other variables to students' performance related to computer usage, such as the computer use in mathematics class, and the use of computers outside of school for schoolwork, and for leisure.

According to the evaluations from the article, the author concludes that solely increasing access to computers for students is unlikely to result in significant improvements in education outcomes.

In our own research, we used the data from the program and RStudio to make multiple linear regression models to seek the answers. [4]

\section{DESCRIPTIVE STATISTICS}

In this research paper, the analysis primarily focuses on the relationship between computer ownership and student achievement. To achieve this goal, we chose the following associated variables to illustrate the relationship. The dependent variable is the 9th year Math and Spanish grades of students, while the independent variable is the computer ownership of students. To better illustrate that relationship, we control variables such as the students' 8th-year grades, whether students have the Internet at home, their mother's education level, whether their father is highly educated, and the family wealth. More importantly, since there are some categorical variables in our data, it's crucial to use some dummy variables.

The datasets for the above variables come from the datasets for Prospera Research. Now, we want to discuss the meanings of those dummy variables. First, there exist two levels on the Internet ("Internet Student $=0$ " means "No Internet", "Internet Student $=1$ " means "Have the Internet"). Besides, there are two levels in the computer ("Computer_Student=0" means "No Computer", "Computer_Student=1" means "Have Computer"). Third, there are nine different levels in both mother education and father education (1 - Did not go to school, 2 Incomplete primary, 3 - Complete primary, 4 Incomplete secondary, 5 - Complete secondary, 6 Baccalaureate or technical career, 7 - Bachelor, 8 Mastery, 9 - Doctorate). Finally, there are six levels in family income per month (1- Less than 1,500 pesos, 2 From 1,500 to 2,999 pesos, 3 - From 3,000 to 7,499 pesos, 4 - From 7,500 to 14,999 pesos, 5 - From 15,000 to 30,000 pesos, 6 - More than 30,000 pesos).

The descriptive table is as follows, which provides some statistical information about our variables.

Table 1. data set from Prospera program.

\begin{tabular}{|c|c|c|c|c|c|c|c|}
\hline Name & Min. & 1st Qu. & Median & Mean & 3rd Qu. & Max. & NA's \\
\hline CAL_ESP10 & 228.3 & 431.9 & 510.2 & 512.3 & 590.1 & 865.0 & \\
\hline CAL_MAT10 & 227.7 & 453.2 & 530.7 & 530.4 & 602.9 & 904.8 & \\
\hline CAL_ESP09 & 217.8 & 436.3 & 505.7 & 509.7 & 581.1 & 851.5 & \\
\hline CAL_MAT09 & 246.4 & 436.9 & 506.8 & 509.7 & 578.1 & 866.7 & \\
\hline Internet_Student & 0.000 & 0.0000 & 0.0000 & 0.3838 & 1.0000 & 1.0000 & 114 \\
\hline Computer_Student & 0.0000 & 0.0000 & 0.0000 & 0.4949 & 1.0000 & 1.0000 & 78 \\
\hline
\end{tabular}




\begin{tabular}{|c|c|c|c|c|c|c|c|}
\hline MomEduc_Parent_all & 1.000 & 3.000 & 4.000 & 4.173 & 6.000 & 9.000 & \\
\hline DadEduc_Parent_all & 1.000 & 3.000 & 4.000 & 4.337 & 6.000 & 9.000 & 399 \\
\hline Famlncome_all & 1.00 & 1.00 & 2.00 & 2.47 & 3.00 & 6.00 & 388 \\
\hline
\end{tabular}

\subsection{Models \& Results}

In this part, we will introduce the model we selected for our examination of the relationship between the 9th Math grades, 9th Spanish grades, and computer ownership. In order to observe these relationships clearly, we choose multiple linear regression as our research model.
As for the 9th Math grades, we built a model called "mod1" to investigate the relationship.

From the above equation, we do the regression based on that model. Then, we can get the following summary results. Based on the results, we can find the coefficient of Computer_Student is 1.1893, which means that we can expect 1.1893 increases in math grades if we increase one unit of computer ownership of students.

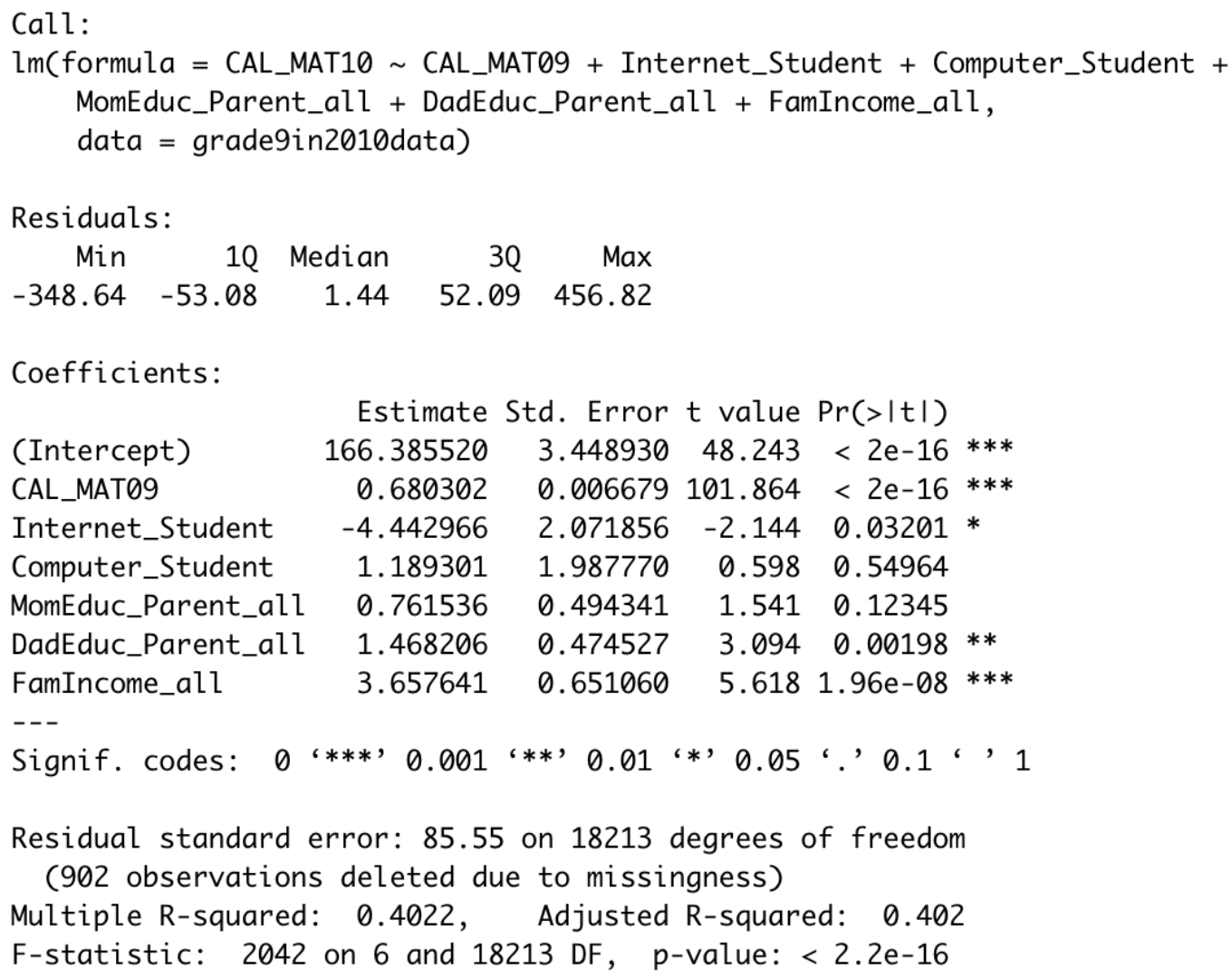

Figure 1 Model run for math grades

As for the 9th Spanish grades, we built a model called "mod2" to investigate the relationship.

From the above equation, we do the regression based on that model. Then, we can get the following summary results. Based on the results, we can find the coefficient of Computer_Student is 5.961327, which means that we can expect 5.961327 increases in Spanish grades if we increase one unit of computer ownership of students. 


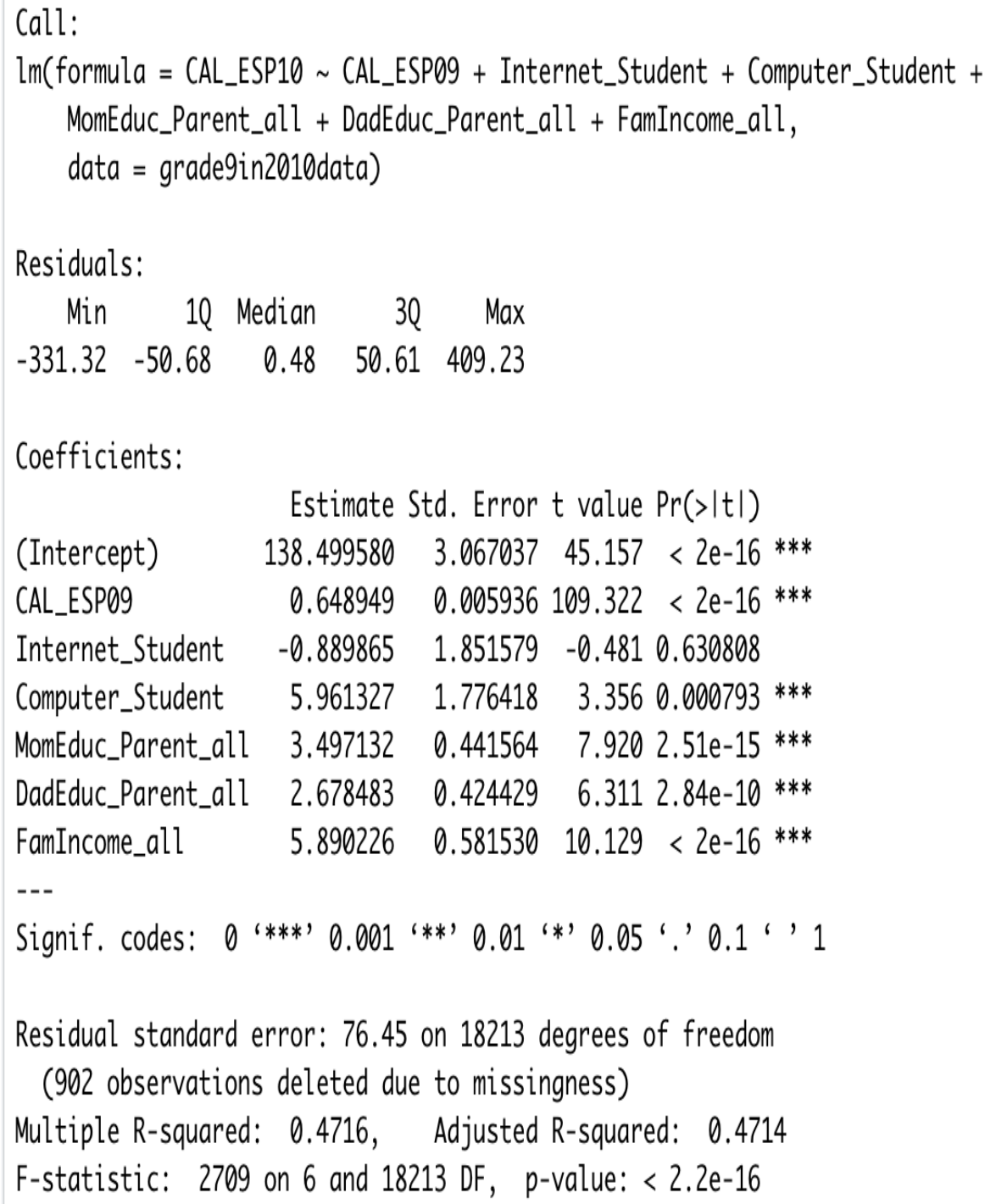

Figure 2 Model run for Spanish grades

Then, to build our model more comprehensive and rigorous, we have to test the importance of some variables. Specifically, it is the family income per month. As we all know, if the family have more income per month, they are more likely to buy students computer and thus affect their final grades. To show that, we build a model called "mod3", which eliminates the variable called "FamInocme_all" in mod1. Then, we can get a new summary table as follows. From that table, we can see that the p-value of Computer_Student is 0.36505 , which is less than that in mod1 0.54964 . Thus, without the family income, the p-value of Computer_Student reduces. So, the family income in our regression does make sense. 


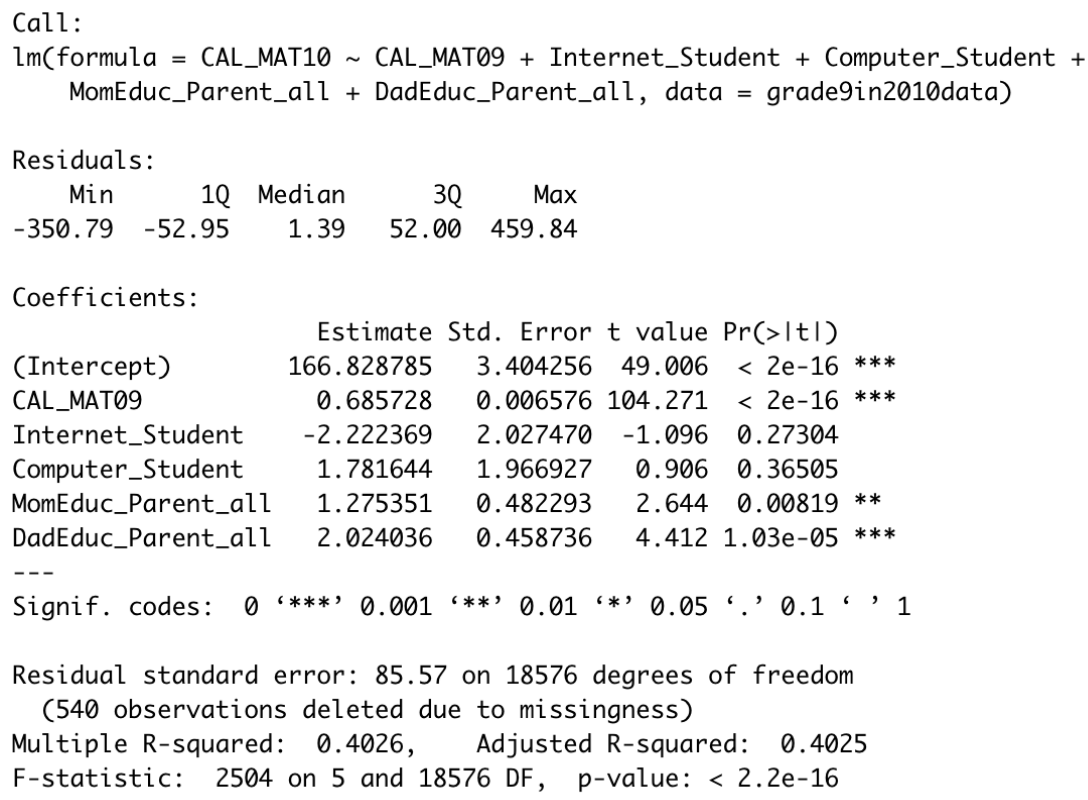

Figure 3 Model run for math grades without family income

Also, as for the family income in $\bmod 2$, we build a model called "mod4". From the following table, we also discover that the p-value is reduced compared to that in mod 2. So, the family income per month does make a significant difference.

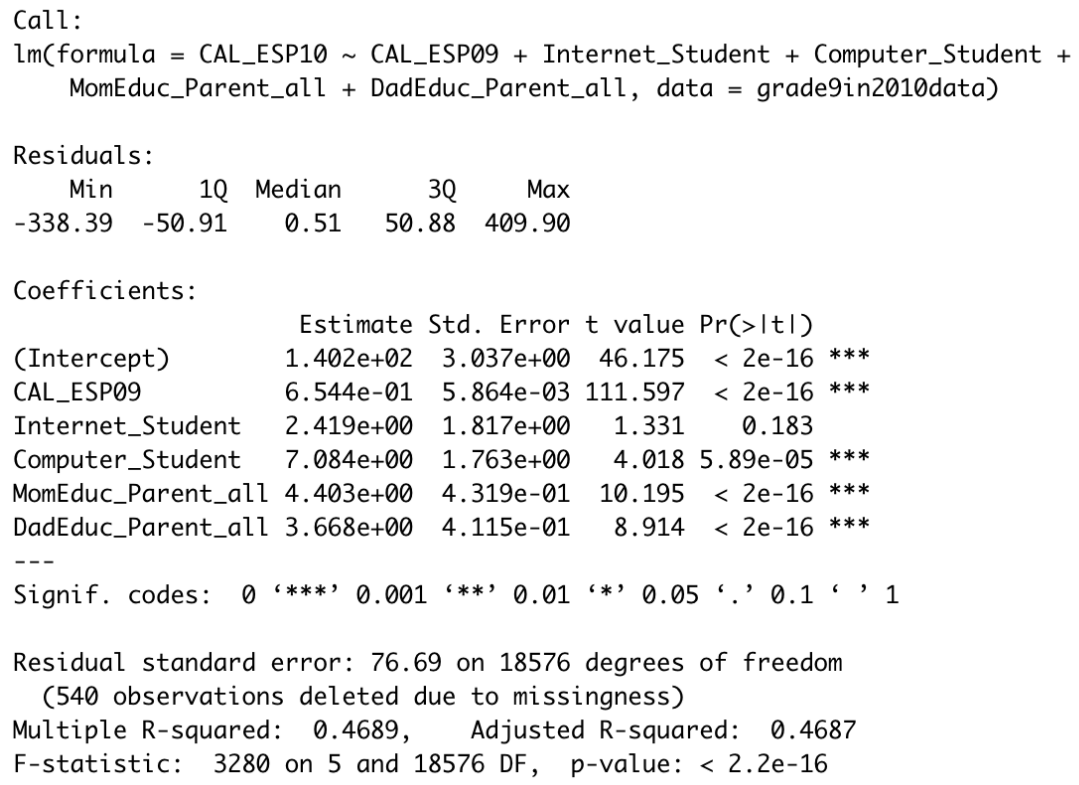

Figure 4 Model run for Spanish grades without family income

After we have done all of our regression models, we actually come out with an interesting result: the important variables are different from Math to Spanish. Firstly, we want to illustrate the different degrees of influence of the two variables, which is Internet_Student and Computer_Student, for 9th grade Math score and Spanish score. We could tell that the $t$ value of Internet_student is less than the Computer_Student, which means that whether or not having Internet at home is more statistically significant and influential to students' Math grade.
However, for students' 9th grade Spanish score, the t value of Computer_Student is less than Internet_Student, which means whether having a computer is more significant instead of internet condition at home. In addition, for students' math scores, we have found out that the father's education level is more important than the mother's education level. In other words, the math score of a student depends more on the education level of the father than the mother's education level. 


\section{CONCLUSION}

In our research progress, we first find out that, according to the article "Do Conditional Cash Transfers Improve Economic Outcomes in the Next Generation?", Progresa can bring significant and long-term effects on the next generation's completed education, work, earnings, and household economic status. Then we conclude from the article "How Computers are Related to Students' Performance" that solely increasing access to computers for students is unlikely to result in significant improvements in education outcomes. However, the result we came up with is quite different with our initial hypothesis, which follows the statement in the previous mentioned articles. In order to find out the real relationships between computer and student's scores, we set up linear regression models in $\mathrm{R}$ studio and analyze part of the data from the Prospera program. After testing for the effect of Computer on mexican students' 9th grade Math and Spanish scores, the result we find out is interesting and unique: having the Internet at home is more statistically significant and influential than having a computer to students' Math grade; for students' 9th grade Spanish score, having access to computers is a more influential factor instead of having internet. As a result, we are surprised to find out that computers affect Math and Spanish scores differently.

\section{REFERENCES}

[1] Rees, Damian. "What Is Ethnography Research?"

Experience UX,

www.experienceux.co.uk/faqs/what-is-

ethnography-research/.

[2] OECD (2015), "How Computers are Related to Students' Performance", in Students, Computers and Learning: Making the Connection, OECD Publishing, Paris.

[3] Parker, Susan W., and Tom Vogl. "Do Conditional Cash Transfers Improve Economic Outcomes in the Next Generation? Evidence from Mexico." NBER, 12 Feb. 2018, www.nber.org/papers/w24303.

[4] Barber, Sarah L, and Paul J Gertler. "The Impact of Mexico's Conditional Cash Transfer Programme, Oportunidades, on Birthweight." Tropical Medicine \& International Health: TM \& IH, U.S. National Library of Medicine, Nov. 2008, www. ncbi.nlm.nih.gov/pmc/articles/PMC2846434/. 